Address for Correspondence: Prof. Nahum Méndez-Sánchez, MD, MSc, PhD. Liver Research Unit, Medica Sur Clinic and Foundation, Puente de Piedra 150, Col. Toriello Guerra, ZP 14050, México City, México. Email: nmendez@medicasur.org.mx

\begin{tabular}{|l|}
\hline Access this article online \\
\hline Website: \\
www.intern-med.com \\
\hline DOI: \\
10.1515/jtim-2017-0031 \\
\hline Quick Response Code: \\
\hline \\
\\
\\
\\
\\
\\
口)
\end{tabular}

\title{
Effects of portal vein thrombosis on the outcomes of liver cirrhosis: A Mexican perspective
}

\author{
Vania Cruz-Ramón, Paulina Chinchilla-López, Oscar Ramírez-Pérez, \\ Nahum Méndez-Sánchez \\ Liver Research Unit, Medica Sur Clinic \& Foundation, Mexico City, Mexico
}

Certainly portal vein thrombosis (PVT) occurs frequently in patients with liver cirrhosis. PVT is a significant milestone in the natural history of cirrhosis, and its prevalence increases with the severity of liver cirrhosis ${ }^{[1]}$. PVT is associated with worsening liver function, gastroesophageal variceal bleeding, and ascites; however, it is unknown whether this association is casual or whether the development of PVT is a further consequence of advanced liver disease.

Several studies have examined the relationship between PVT and liver cirrhosis. The estimated worldwide prevalence of PVT in cirrhotics is 0.6$26 \%$, and the frequency increases in patients with decompensated cirrhosis ${ }^{[1-5]}$. Autopsy studies have reported a prevalence of $6-64 \%{ }^{[6]}$. In Mexico, the reported prevalence is $7.6 \%{ }^{[7]}$, which is within the range reported in the literature ${ }^{[8-9]}$. In addition, liver cirrhosis is considered to be the 14th most common cause of death worldwide $^{[10]}$, 12th in United States ${ }^{[11-12]}$, the fourth in Central Europe ${ }^{[13]}$ and in Mexico $^{[14]}$.

Advanced cirrhosis is associated with a complex variety of coagulation defects that affect procoagulant and anticoagulant factors, the fibrinolytic system, and platelet number and function ${ }^{[15]}$. The outcomes of all these defects may be a prothrombotic state, which is likely to be related to the increased endothelial cell synthesis of von Willebrand factor and an increased level of factor VIII combined with low levels of hepatic anticoagulation agents such as proteins
$\mathrm{C}$ and $\mathrm{S}$, and antithrombin III ${ }^{[16,17]}$. Many studies have identified various inherited and acquired disorders as predisposing factors for PVT in patients with cirrhosis. These include proteins $\mathrm{S}$ and $\mathrm{C}$ deficiency, antithrombin deficiency, factor $\mathrm{V}$ Leiden G1691A mutation, myeloproliferative disorders, and prothrombin G20210A mutation $^{[18-22]}$. In this regard, it has reported that the prevalence of thrombophilic disorders is lower in cirrhotic patients than in non-cirrhotic patients ${ }^{[23-24]}$. However, the role and frequency of thrombophilic genetic risk factors in cirrhotic patients are not well known ${ }^{[24]}$. On the other hand, some studies have shown that thrombophilia is a significant risk factor for developing PVT in non-cirrhotic patients. In Mexico, Majluf-Cruz et al. studied 36 noncirrhotic patients who had thrombosis-related portal hypertension and found an incidence of $30 \%$ of protein $\mathrm{C}$ deficiency, whereas $9 \%$ had protein S deficiency in patients with primary thrombophilia ${ }^{[25]}$. Another Mexican group reported a similar incidence $(31 \%)$ of protein $\mathrm{C}$ deficiency in noncirrhotic patients with PVT. These findings suggest that protein $\mathrm{C}$ deficiency should be investigated in all patients with PVT, especially in those with a history of thromboembolic disease ${ }^{[26]}$.

On examining the PVT outcomes in patients with liver cirrhosis, Harding et al. ${ }^{[27]}$ noted that extension of PVT affects the rates of complications and survival after liver transplantation, wherefore the Yerdel classification is currently used to correlate portal vein thrombosis extension with surgical techniques and 
risk of complications ${ }^{[28]}$. By contrast, Luca et al. reported high rates of PVT regression instead of uniform thrombus progression ${ }^{[29]}$. They also found that thrombotic progression did not correlate with an increase in mortality, episodes of hepatic decompensation, or the need for liver transplantation. The studies by Nery et al. and BorjasAlmaguer's group support these findings because they also found that the presence of PVT did not worsen the prognosis for cirrhosis, at least in cirrhotic patients with nonmalignant PVT ${ }^{[7,30]}$. However, these studies have important limitations such as the follow-up time of Lucas's study was only of 27 months. Also a large part of their sample has partial PVT. Then, probably partial PVT progressed more slowly than their follow-up time so they might not be able to detect the progression to complete PVT. Likewise, Borjas-Almaguer's group realized a retrospective study so they probably did not have all necessary data to ensure their outcomes. Consequently, there is some controversy about whether PVT influences the mortality rate in cirrhotic patients or whether PVT reduces the opportunity to be considered as candidate for liver transplantation. Therefore, it can be inferred that the relationship between the progression or regression of PVT and clinical outcomes according to the initial Child-Pugh score is unclear.

The presence of PVT is associated with a longer time to achieve endoscopic eradication of varices and the risk of developing an intestinal infarction if the mesenteric vein and its branches are involved ${ }^{[31-33]}$. These complications are very important for the prognosis of liver cirrhosis because it is well known that variceal bleeding has a 6-week mortality rate of $15-20 \%{ }^{[34-35]}$, and intestinal infarction has a mortality rate of up to $6 \%^{[36]}$. These manifestations may become fatal without a rapid and correct diagnosis and adequate treatment. In addition, clinicians need to be aware of a sudden clinical deterioration in a cirrhotic patient, such as the development of bacterial peritonitis or of diureticresistant ascites because these could be manifestations, or the trigger, of PVT development ${ }^{[27,37]}$.

In Mexico, some studies have investigated PVT in patients with cirrhosis. In a retrospective Mexican study, BorjasAlmaguer et al. ${ }^{[7]}$ investigated the relevance of PVT not associated with malignancy to clinical outcomes in cirrhotic patients. They reported that patients with PVT were younger and had lower Child-Pugh score, and model for end-stage liver disease scores compared with patients without PVT as well as they observed that alcohol was the most predominant etiology of liver cirrhosis. They also reported that PVT by itself was not associated with a worse prognosis in terms of survival, upper gastrointestinal bleeding, spontaneous bacterial peritonitis, large-volume ascites, or encephalopathy even if not treated with anticoagulation treatment. Likewise, they suggested that the presence of PVT may be an epiphenomenon and not necessarily a marker of an advanced liver disease. On the other hand, our group performed a retrospective study with 67 patients diagnosed with thrombosis of the portal vein system (PVST), categorized in cirrhotic and non-cirrhotic patients, to evaluate risk factors for developing PVST. Consequently, in our analyses between the two groups we observed that most of the patients with cirrhosis had a high MELD score, which as we know is a predictor of prognosis in chronic liver disease, added to this; half of them had hepatocellular carcinoma (HCC) and the main cause of liver cirrhosis in them was nonalcoholic steatohepatitis. Therefore, our research findings suggest that the outcomes in patients with HCC and MELD score $>15$ could not be favorable ${ }^{[38]}$.

A retrospective study by Bermejo et al. in Mexico ${ }^{[39]}$ of the complications in critically ill cirrhotic patients reported a higher incidence of hemorrhagic complications (48.5\%) than thrombotic complications (13.66\%). However, this may have been because their patients had Child-Pugh class A or B status, and the study did not include complete imaging screening.

Finally, it is important to mention that in relation to PVT treatment, the results of the prophylactic therapy for patients with cirrhosis based on low doses of enoxaparin has been promising because it has been observed that it has a protective role in the development of PVT. However, the new class of anticoagulants, direct oral anticoagulants (DOACs), will change in the near future the monitoring for patients who received prophylactic treatments. Some of the advantages of DOACs are that they are taken by oral administration; they have fewer drug interactions and no required blood monitoring. Nevertheless, the main side effect of these drugs is an uncontrolled bleeding but currently their adverse events have been studied, and new drugs proposed to reverse the anticoagulant effect ${ }^{[40]}$.

In conclusion, PVT could be an unfortunate clinical evolution of liver cirrhosis and may be a sign or cause of decompensation. However, many important questions remain unanswered despite significant advances in diagnosis and treatment of PVT in cirrhotic patients. Further studies are needed to investigate whether PVT has a role as prognostic factor of liver cirrhosis as well to establish the risk-benefit ratio of anticoagulant treatment in cirrhotic and non-cirrhotic patients, including the safety and efficacy of new oral anticoagulants. Especially in Mexico, more studies should be realized due to liver cirrhosis has a high mortality rate in our country (fourth place) and as we described this type of population are most at risk to develop PVT. 


\section{Disclosure}

All authors of this manuscript declare that they have been read and approved the full paper and there is no conflict of interest.

\section{REFERENCES}

1. Amitrano L, Guardascione MA, Brancaccio V, Margaglione M, Manguso F, Iannaccone L, et al. Risk factors and clinical presentation of portal vein thrombosis in patients with liver cirrhosis. J Hepatol 2004; 5:736-41.

2. Okuda K, Ohnishi K, Kimura K, Matsutani S, Sumida M, Goto N, et al. Incidence of portal vein thrombosis in liver cirrhosis. An angiographic study in 708 patients. Gastroenterology 1985; 2: 279-86.

3. Belli L, Romani F, Sansalone CV, Aseni P, Rondinara G. Portal thrombosis in cirrhotics. A retrospective analysis. Ann Surg 1986; 3: 286-91.

4. Tsochatzis EA, Senzolo M, Germani G, Gatt A, Burroughs AK. Systematic review: Portal vein thrombosis in cirrhosis. Aliment Pharmacol Ther 2010; 3: 366-74.

5. Rajani R, Björnsson E, Bergquist A, Danielsson A, Gustavsson A, Grip O, et al. The epidemiology and clinical features of portal vein thrombosis: A multicentre study. Aliment Pharmacol Ther 2010; 9: 1154-62.

6. Fimognari FL, Violi F. Portal vein thrombosis in liver cirrhosis. Intern Emerg Med 2008; 3: 213-8.

7. Borjas-Almaguer OD, Cortez-Hernández CA, González-Moreno EI, Bosques-Padilla FJ, González-González JA, Garza AA, et al. Portal vein thrombosis in patients with cirrhosis: Just a common finding or a predictor of poor outcome? Ann Hepatol 2016; 6: 902-6.

8. Nonami T, Yokoyama I, Iwatsuki S, Starzl TE. The incidence of portal vein thrombosis at liver transplantation. Hepatology1992; 5: 1195-8.

9. Ogren M, Bergqvist D, Bjorck M, Acosta S, Eriksson H, Sternby NH. Portal vein thrombosis: Prevalence, patient characteristics and lifetime risk: A population study based on 23, 796 consecutive autopsies. World J Gastroenterol 2006; 13: 2115-9.

10. Lopez AD, Mathers CD, Ezzati M, Jamison DT, Murray CJ. Global and regional burden of disease and risk factors, 2001: Systematic analysis of population health data. Lancet 2006; 9524: 1747-57.

11. Yoon YH, Chen MC. Liver cirrhosis mortality in the United States: National, state, and regional trends, 2000-2013. National Institute on Alcohol Abuse and Alcoholism, Surveillance Report \#105, 2016: 1-71. Available from: https://pubs.niaaa.nih.gov/publications/surveillance105/ Cirr13.pdf. Accessed on November 6, 2017.

12. Starr P, Raines D. Cirrhosis: Diagnosis, management, and prevention. Am Fam Physician 2011; 12: 1353-9.

13. Tsochatzis EA, Bosch J, Burroughs AK. Liver cirrhosis. Lancet 2014; 9930: 1749-61.

14. Mokdad AA, Lopez AD, Shahraz S, Lozano R, Mokdad AH, Stanaway J, et al. Liver cirrhosis mortality in 187 countries between 1980 and 2010: A systematic analysis. BMC Med 2014; 12: 145.

15. Tripodi A, Mannucci PM. The coagulopathy of chronic liver disease. New Engl J Med 2011; 2: 147-56.

16. Ferro D, Quintarelli C, Lattuada A, Leo R, Alessandroni M, Mannucci PM, et al. High plasma levels of von Willebrand factor as a marker of endothelial perturbation in cirrhosis: Relationship to endotoxemia. Hepatology 1996; 6: 1377-83.

17. Tripodi A, Anstee QM, Soogaard KK, Primignani M, Valla DC. Hypercoagulability in cirrhosis: Causes and consequences. J Thromb Haemost 2011; 9: 1715-23.

18. Amitrano L, Brancaccio V, Guardascione MA, Margaglione M, Iannaccone L, D'Andrea Get al. Inherited coagulation disorders in cirrhotic patients with portal vein thrombosis. Hepatology 2000; 2: 345-8.

19. Dentali F, Galli M, Gianni M, Ageno W. Inherited thrombophilic abnormalities and risk of portal vein thrombosis. A meta-analysis. J Thromb Haemost 2008; 4: 675-82.
20. Tripodi A, Primignani M, Lemma L, Chantarangkul V, Mannucci PM. Evidence that low protein $\mathrm{C}$ contributes to the procoagulant imbalance in cirrhosis. J Hepatol 2013; 2: 265-70.

21. Manzano-Robleda MC, Barranco-Fragoso B, Uribe M, Méndez-Sánchez N. Portal vein thrombosis: What is new? Ann Hepatol 2015; 1: 20-7.

22. Muciño-Bermejo J, Carrillo-Esper R, Uribe M, Méndez-Sánchez N. Coagulation abnormalities in the cirrhotic patient. Ann Hepatol 2013; 5: 713-24.

23. Primignani M, La Mura V. Diagnosis of thrombophilia/prothrombotic conditions in patients with liver disease. Clin Liver Dis 2014; 6: 126-8.

24. Saugel B, Lee M, Feichtinger S, Hapfelmeier A, Schmid RM, Siveke JT. Thrombophilic factor analysis in cirrhotic patients with portal vein thrombosis. J Thromb Thrombolysis 2015; 1: 54-60.

25. Majluf-Cruz A, Hurtado-Monroy R, Sansores-García L,LabardiniMéndez J. The incidence of protein $\mathrm{C}$ deficiency in thrombosis-related portal hypertension. Am J Gastroenterol 1996; 5: 976-80.

26. Orozco H, Guraieb E, Takahashi T, Garcia-Tsao G, Hurtado R, Anaya $\mathrm{R}$,et al., Deficiency of protein $\mathrm{C}$ in patients with portal vein thrombosis. Hepatology 1988; 5: 1110-1.

27. Harding DJ, Perera MT, Chen F, Olliff S, Tripathi D. Portal vein thrombosis in cirrhosis: Controversies and latest developments. World J Gastroenterol 2015; 22: 6769-84.

28. Yerdel MA, Gunson B, Mirza D, Karayalçin K, Olliff S, Buckels J, et al. Portal vein thrombosis in adults undergoing liver transplantation: Risk factors, screening, management, and outcome. Transplantation 2000; 9:1873-81.

29. Luca A, Caruso S, Milazzo M, Marrone G, Mamone G, Crinò F, et al. Natural course of extrahepatic nonmalignant partial portal vein thrombosis in patients with cirrhosis. Radiology 2012; 1:124-32.

30. Nery F, Chevret S, Condat B, De Raucourt E, Boudaoud L, Rautou PE, et al. Causes and consequences of portal vein thrombosis in 1,243 patients with cirrhosis: Results of a longitudinal study. Hepatology 2015; 2:660-7.

31. Dell'Era A, Iannuzzi F, Fabris FM, Fontana P, Reati R, Grillo P,et al. Impact of portal vein thrombosis on the efficacy of endoscopic variceal band ligation. Dig Liver Dis 2014; 2:152-6.

32. Kocher G, Himmelmann A. Portal vein thrombosis (PVT): A study of 20 non-cirrhotic cases. Swiss Med Wkly 2005; 25: 372-6.

33. Kumar S, Sarr MG, Kamath PS. Mesenteric venous thrombosis. N Engl J Med 2001; 23:1683-8.

34. Garcia-Tsao G, Bosch J. Management of varices and variceal hemorrhage in cirrhosis. N Engl J Med 2010; 9: 823-32.

35. Tripathi D, Stanley AJ, Hayes PC, Patch D, Millson C, Mehrzad H, et al. U.K. guidelines on the management of variceal haemorrhage in cirrhotic patients. Gut 2015; 11: 1680-704.

36. Von Köckritz L, De Gottardi A, Trebicka J, Praktiknjo M. Portal vein thrombosis in patients with cirrhosis. Gastroenterol Rep 2017; 2:148-56.

37. Trebicka J, Strassburg CP. Etiology and complications of portal vein thrombosis. Viszeralmedizin 2014; 6: 375-80.

38. Chinchilla-López P, Cruz-Ramón V, Ramírez-Pérez O, Aguilar-Olivos NE, Alva-López LF, Fajardo-Ordoñez E, et al. Liver cirrhosis and its severity as predictor factor for thrombosis in the portal venous system. Am J Gastroenterol 2017; 112: S556.

39. Muciño-Bermejo J, Carrillo-Esper R, Méndez-Sánchez N, Uribe M. Thrombosis and hemorrhage in the critically ill cirrhotic patients: Five years retrospective prevalence study. Ann Hepatol 2015; 1: 93-8.

40. Chinchilla-López P, Baptista-González H, Intagliata NM, Northup PG, Stephen $\mathrm{H}$. Caldwell SH, et al. The direct oral anticoagulants in patients with and without liver disease. AME Med J 2017; 2: 44.

How to cite this article: Cruz-Ramón V, Chinchilla-López P, RamírezPérez $O$, Méndez-Sánchez N. Effects of portal vein thrombosis on the outcomes of liver cirrhosis: A Mexican perspective. J Transl Intern Med 2017; 5: 189-91. 